\title{
Relationship of tumor size with pathological and prognostic factors for hilar cholangiocarcinoma
}

\author{
Hai-Jie Hu ${ }^{1, *}$, Rong-Xing Zhou ${ }^{1, *}$, Anuj Shrestha ${ }^{1,2}$, Yong-Qiong Tan ${ }^{1}$, Wen-Jie Ma ${ }^{1}$, \\ Qin Yang ${ }^{1}$, Jiong Lu ${ }^{1}$, Jun-Ke Wang ${ }^{1}$, Yong Zhou ${ }^{1}$ and Fu-Yu Li ${ }^{1}$ \\ ${ }^{1}$ Department of Biliary Surgery, West China Hospital of Sichuan University, Chengdu, Sichuan Province, China \\ ${ }^{2}$ Department of General Surgery, Gandaki Medical College, Pokhara, Nepal \\ *Co-author and contributed equally to this work \\ Correspondence to: Fu-Yu Li, email: Ify_74@hotmail.com \\ Yong Zhou, email: 1063557621@qq.com
}

Keywords: hilar cholangiocarcinoma, prognostic factors, DeOliveira staging system, tumor size, survival outcome

Received: June 08, $2017 \quad$ Accepted: September 23, $2017 \quad$ Published: October 23, 2017

Copyright: Hu et al. This is an open-access article distributed under the terms of the Creative Commons Attribution License 3.0 (CC BY 3.0), which permits unrestricted use, distribution, and reproduction in any medium, provided the original author and source are credited.

\section{ABSTRACT}

Objective: To determine the correlation of different tumor-size cutoffs with prognostic factors and survival outcomes to provide a reference for the modification of the T-stage classification in the DeOliveira staging system for hilar cholangiocarcinoma (HCCA).

Materials and Methods: We retrospectively analyzed 216 patients who underwent curative surgery for HCCA (mean tumor diameter, $2.8 \mathrm{~cm}$ ) between 2000 and 2013. Univariate and multivariate logistic regression were used to assess the correlation of tumor-size cutoffs with various factors.

Results: Tumor differentiation (odds ratio [OR]: 1.649, 95\% confidence interval [CI]: 1.065-2.555, $P=0.025$ ), node status (OR: 1.971, 95\% CI: 1.060-3.664, P $=0.032$ ), resection margin (OR: 2.465, 95\% CI: 1.024-5.937, $P=0.044$ ), and hepatectomy (OR: 2.373, 95\% CI: 1.226-4.593, $P=0.01$ ) were independently correlated with the $2-\mathrm{cm}$ cutoff, while tumor differentiation (OR: 1.755, 95\% CI: 1.062-2.091, $P=0.028$ ), node status (OR: 2.166, 95\% CI: 1.054-4.452, $P=0.035$ ), and tumor margin (OR: 2.539, 95\% CI: 1.089-5.919, $P=0.031$ ) were independently associated with the $3-\mathrm{cm}$ cutoff.

Conclusions: The $2-\mathrm{cm}$ and $3-\mathrm{cm}$ cutoffs were strongly correlated with resection margin, node status, tumor differentiation and survival. The $2-\mathrm{cm}$ cutoff may be added to the DeOliveira staging system.

\section{INTRODUCTION}

Hilar cholangiocarcinoma (HCCA) is a comparatively infrequent neoplasm typically involving the confluence of the hepatic ducts [1]. Owing to their location at the confluence of the right and left bile ducts and their close relationship with major vascular structures, these tumors tend to invade the portal vein, hepatic artery, and liver parenchyma, resulting in a relatively low surgicalresectability rate of $34 \%-47.2 \%$ [2-4]. In addition, risk factors like preoperative liver dysfunction, obstructive jaundice, and long operative time increase the surgical risks and decrease the surgical-resection and survival rates. Despite this, the standard treatment for HCCA is bileduct resection accompanied with hepatectomy, caudate lobectomy, lymphadenectomy, and even vascular resection and reconstruction [5-9]. HCCA-resection surgery is one of the most difficult and challenging surgical procedures performed by hepatobiliary surgeons because HCCA demonstrates a propensity for intramural growth, perineural invasion, and regional and distant lymphatic infiltration [8, 10]. The reported 5-year survival rates vary from $10 \%$ to $40 \%$, which is far from satisfactory [1, 11-19].

Many prognostic factors such as lymph node status, tumor differentiation, margin status, and caudate lobectomy have been reported to influence survival outcomes in HCCA [6, 15, 20-23]. Tumor size is a controversial prognosticator; several studies have reported no correlation of tumor size with survival [4, 11, 24-26], while others have found that smaller tumors are associated with better survival results than larger tumors [22, 27-30]. In fact, the DeOliveira staging system for HCCA distinguishes 
between T1, T2, and T3 tumors solely on the basis of tumor diameter $(<1 \mathrm{~cm}$ vs. $1-3 \mathrm{~cm}$ vs. $>3 \mathrm{~cm})[29,31]$.

The DeOliveira staging system is now accepted as a classification system for HCCA. However, the practical ability of the staging system to predict the nature of the tumor or the postoperative survival outcomes remains to be further improved [31, 32]. In addition, few studies have specifically analyzed the correlation of tumor size with pre- and postoperative prognostic factors, and the influence of tumor size on clinical and pathological variables remains unclear. Actually, any staging system including the DeOliveira staging system, is undoubtedly not so comprehensive, thus further research is required to determine the relationship of different tumor sizes with various tumor factors in order to provide a reliable basis for the future definition of the $T$ stage in the DeOliveira staging system.

We, therefore, conducted a single-center large-scale case series study that aimed to determine the relationship of different tumor-size cutoff points with various clinical and pathological variables as well as survival rates in order to evaluate the possibility of implementing another tumorsize cutoff of $2 \mathrm{~cm}$ or $4 \mathrm{~cm}$ in addition to the current $1-\mathrm{cm}$ and $3-\mathrm{cm}$ cutoff points of the DeOliveira staging system.

\section{RESULTS}

\section{Patient characteristics}

The study involved 216 HCCA patients, including 140 men and 76 women, with a median age of 60 years (range, 26-82 years). The clinical characteristics of the patients are shown in Table 1 . The most common symptom was jaundice $(60 \%)$. The median intraoperative blood loss was $600 \mathrm{~mL}$ (range, 50-2000 mL), and 103 $(47.7 \%)$ patients required perioperative blood transfusion. Preoperative biliary drainage was performed in 107 (49.5\%) patients with jaundice, and 30 (13.9\%) patients underwent preoperative portal vein embolization. According to the AJCC staging system, 34, 76, 81, and 25 patients had stage I, II, III, and IV disease, respectively. According to the Bismuth-Corlette classification, 55, 52, 57, and 52 patients had type I, II, III, and IV disease, respectively. The perioperative morbidity rate was $31.9 \%$ $(n=69)$, and the most common perioperative complication was bile leakage $(n=25)$. The perioperative mortality rate was $2.3 \%(n=5)$, which was defined as death within $60 \mathrm{~d}$ of the surgery, or occurred at any time during the postoperative hospital stay.

\section{Histopathology}

On the postoperative pathological examination, all tumors were identified as adenocarcinomas. The tumor diameters ranged from $1 \mathrm{~cm}$ to $8 \mathrm{~cm}$ (median, $2.8 \mathrm{~cm}$ ). With regard to the gross features, the most common phenotype was infiltrating tumor ( $n=145,67.1 \%$ ), followed by nodular tumor $(n=51,23.6 \%)$ and papillary tumor $(n=20,9.3 \%)$. The margin status was R0 in 176 $(81.5 \%)$ patients and R1 in $40(18.5 \%)$ patients. In terms of tumor differentiation, $61(28.2 \%)$ tumors were well differentiated, 99 (45.8\%) were moderately differentiated, and $56(26.0 \%)$ were poorly differentiated. Histologically negative lymph nodes were found in 56\% (121/216) of patients.

\section{Survival}

The median follow-up time was 21 months (range, 3-85 months). After resection, the median overall survival time was 26 months, and the 1-, 3-, and 5-year survival rates were $79 \%, 42 \%$, and $27 \%$, respectively (Figure 1 ). The median disease-free survival time was 17 months, and the 1-, 3-, and 5-year disease-free survival rates were $72 \%, 20 \%$, and $11 \%$, respectively. The factors that could predict survival outcomes are presented in Table 2. Among these factors, the $2-\mathrm{cm}$ and $3-\mathrm{cm}$ tumor-size cutoffs were independently associated with survival in both the univariate and multivariate analyses, while the $1-\mathrm{cm}$ and 4-cm cutoffs failed to predict survival $(P>0.05)$.

\section{Relationship between tumor size and other tumor characteristics}

The relationship of the $2-\mathrm{cm}$ and $3-\mathrm{cm}$ tumor-size cutoffs with various tumor characteristics is presented in Table 3. The univariate logistic regression showed that the $2-\mathrm{cm}$ cutoff was significantly correlated with tumor differentiation $(P=0.008)$, tumor-free resection $(P=0.009)$, node status $(P=0.001)$, preoperative hospital stay $(P=0.009)$, total hospital stay $(P=0.002)$, vascular invasion $(P=0.036)$, caudate lobectomy $(P=$ $0.047)$, hepatectomy $(P=0.046)$, the AJCC T stage $(P$ $=0.005)$, and the Bismuth-Corlette classification $(P=$ 0.04). Similarly, the univariate logistic regression also showed that tumor differentiation $(P<0.001)$, tumorfree resection $(P=0.005)$, node status $(P=0.002)$, gross features $(P=0.021)$, preoperative hospital stay $(P=0.001)$, total hospital stay $(P=0.003)$, and vascular invasion $(P=0.021)$ were independently associated with the $3-\mathrm{cm}$ tumor-size cutoff. However, in the subgroup of patients with tumors measuring $\leq 2 \mathrm{~cm}$, no factors were identified to correlate with the $1-\mathrm{cm}$ cutoff $(P>0.05)$. Similarly, no factors were associated with the 4-cm cutoff in the subgroup of patients with tumors measuring $>3 \mathrm{~cm}$ $(P>0.05)$.

Factors with $p$ values $<0.1$ from the univariate analysis were entered into in the multivariate analysis (Table 4). The multivariate analysis showed that tumor differentiation (odds ratio [OR]: 1.649, 95\% confidence interval [CI]: $1.065-2.555, P=0.025$ ), node status (OR: 1.971, 95\% CI: $1.060-3.664, P=0.032)$, tumor resection margin (OR: 2.465, 95\% CI: $1.024-5.937, P=0.044$ ), 
Patient Characteristics $(n=216)$

Variables

Number $(\%)$ or median [range]

\begin{tabular}{|c|c|}
\hline Age & $60[26-82]$ \\
\hline Gender, male & $140(64.8)$ \\
\hline \multicolumn{2}{|l|}{ Preoperative laboratory data } \\
\hline Preoperative CA 19-9 level,U/ml & $348[0.6-1000]$ \\
\hline Preoperative CA 125 level,U/ml & $19.84[1.23-257.7]$ \\
\hline Preoperative CEA level, ng/ml & $3.23[0.2-65.51]$ \\
\hline Preoperative TB level, mg/dL & $10.2[0.41-34.3]$ \\
\hline Preoperative ALT level,U/L & 95 [10-967] \\
\hline Preoperative AST level, U/L & $86[14-1016]$ \\
\hline Preoperative Albumin level, $\mathrm{g} / \mathrm{L}$ & $36.7[18.7-51.8]$ \\
\hline Preoperative hospital stay (median [range]) & $8[2-44]$ \\
\hline Total hospital stay (median [range]) & 19 [9-113] \\
\hline Estimated blood loss, median [range] & $600[50-2000]$ \\
\hline \multicolumn{2}{|l|}{ Tumor extent (Bismuth-Corlette) } \\
\hline Type I & $55(25.4)$ \\
\hline Type II & $52(24.1)$ \\
\hline Type IIIa or IIIb & $57(26.4)$ \\
\hline Type IV & $52(24.1)$ \\
\hline \multicolumn{2}{|l|}{ AJCC T Stage } \\
\hline $\mathrm{T} 1$ & $34(15.7)$ \\
\hline $\mathrm{T} 2$ & $76(35.2)$ \\
\hline $\mathrm{T} 3$ & $81(37.5)$ \\
\hline $\mathrm{T} 4$ & $25(11.6)$ \\
\hline \multicolumn{2}{|l|}{ DeOliveira T Stage } \\
\hline $\mathrm{T} 1$ (Tumor size $\leq 1 \mathrm{~cm})$ & $21(9.7)$ \\
\hline T2 (Tumor size $1-3 \mathrm{~cm}$ ) & $145(67.1)$ \\
\hline T3 $($ Tumor size $>3 \mathrm{~cm}$ ) & $50(23.1)$ \\
\hline
\end{tabular}

CA19-9: carbohydrate antigenic determinant 19-9; CA125: carbohydrate antigen 125; CEA: Carcino Embryonie Antigen; TB: total bilirubin; ALT: alanine aminotransferase. AST: aspartate transaminase; AJCC: American Joint Committee On Cancer.

hepatectomy (OR: 2.373, 95\% CI: 1.226-4.593, $P=0.01$ ), and total hospital stay (OR: $2.428,95 \%$ CI: $1.327-4.441$, $P=0.004$ ) were independently associated with the $2-\mathrm{cm}$ cutoff. However, other factors like preoperative hospital stay (OR: 1.671, 95\% CI: 0.798-3.489, $P=0.17$ ), vascular invasion (OR: 0.796, 95\% CI: 0.274-2.313, $P=0.67$ ), the AJCC T stage (OR: 1.585, 95\% CI: 0.829-3.030, $P=0.16$ ), the Bismuth-Corlette classification (OR: 1.154, 95\% CI: $0.544-2.451, P=0.79)$, and caudate lobectomy (OR: $1.649,95 \%$ CI: $0.780-3.484, P=0.19$ ) failed to maintain a significant statistical difference in the multivariate analysis. In addition, the multivariate analysis showed that tumor differentiation (OR: 1.755, 95\% CI: 1.062-2.091, $P=$ 0.028), node status (OR: $2.166,95 \%$ CI: $1.054-4.452, P=$ 0.035 ), tumor resection margin (OR: $2.539,95 \%$ CI: 1.089 $5.919, P=0.031$ ), and total hospital stay (OR: $2.383,95 \%$ CI: $1.072-5.295, P=0.033)$ were independently associated with the 3-cm cutoff. However, gross pathological features (OR: 0.773, 95\% CI: $0.427-1.399, P=0.394$ ), preoperative hospital stay (OR: 1.980, 95\% CI: $0.890-4.403, P=0.094)$, and vascular invasion (OR: $0.519,95 \%$ CI: $0.198-1.359$, $P=0.182$ ) were not significantly associated with the $3-\mathrm{cm}$ cutoff in the multivariate analysis.

\section{DISCUSSION}

HCCA is a highly fatal disease. Despite rapid developments in surgical techniques and perioperative care, the resection of HCCA remains challenging. The prognostic factors for HCCA have been extensively researched. However, to our knowledge, the relationship of different tumor sizes with prognostic factors such as pathological classification, nodal status, resection margins and survival, has not yet been investigated in detail. Moreover, different authors hold different 
Table 2: Univariate and multivariate analysis of factors associated with long-term survival after resection of hilar cholangiocarcinoma

\begin{tabular}{|c|c|c|c|c|c|c|}
\hline \multirow{2}{*}{$\begin{array}{l}\text { Prognostic factors } \\
P \text { value }\end{array}$} & & \multicolumn{2}{|c|}{ Univariate analysis } & \multicolumn{3}{|c|}{ Multivariate analysis } \\
\hline & & $\begin{array}{l}\text { Hazard } \\
\text { ratio }\end{array}$ & $95 \% \mathrm{CI}$ & $P$ value & Hazard ratio & $95 \% \mathrm{CI}$ \\
\hline \multicolumn{7}{|l|}{ Tumor size } \\
\hline$\leq 2 \mathrm{~cm}$ & \multicolumn{3}{|c|}{ Reference } & \multicolumn{3}{|c|}{ Reference } \\
\hline $2-3 \mathrm{~cm}$ & 0.045 & 1.406 & $1.008-1.959$ & 0.007 & 1.596 & $1.135-2.244$ \\
\hline$>3 \mathrm{~cm}$ & $<0.001$ & 2.107 & $1.442-3.079$ & 0.009 & 1.700 & $1.140-2.535$ \\
\hline Positive nodal status & $<0.001$ & 1.884 & $1.410-2.517$ & 0.002 & 1.602 & $1.184-2.169$ \\
\hline Poor differentiation & $<0.001$ & 2.887 & $1.950-4.275$ & $<0.001$ & 2.449 & $1.671-3.738$ \\
\hline Positive resection margin & $<0.001$ & 2.490 & $1.724-3.595$ & $<0.001$ & 2.266 & $1.513-3.393$ \\
\hline
\end{tabular}

Additional factors not significant on univariate analysis included age, gender, the $1 \mathrm{~cm}$ and $4 \mathrm{~cm}$ tumor size cut-off, AJCC tumor stage, gross feature et al.

views about the prognostic effects of tumor size and the T stage of the DeOliveira staging system, and whether or not 2-cm and 4-cm cutoffs should be included in the T stage of the DeOliveira staging system remains debatable. Some studies have reported that a tumor size of $\geq 2 \mathrm{~cm}$ is associated with worse survival outcomes $[22,33]$. Therefore, in the present study, we assessed tumor-size cutoffs of $1,2,3$, and $4 \mathrm{~cm}$, so as to determine the relationship of tumor size with various prognostic factors and survival outcomes. Our study comprises a single-center largescale case series of HCCA patients treated over a period of 10 years. Thus, it is the first large-scale case series to specifically evaluate the relationship of different tumor-size cutoffs with pathological and prognostic factors in a large sample of HCCA cases. We hope that our results will provide a basis for the reevaluation of the $\mathrm{T}$ stage in the DeOliveira staging system.

The specific analysis of the relationship of different tumor-size cutoffs with tumor differentiation showed that the $2-\mathrm{cm}$ and $3-\mathrm{cm}$ cutoffs were correlated with tumor differentiation, with larger tumors being more likely to be poorly differentiated. However, the 1-cm and 4-cm cutoffs showed no correlation with tumor differentiation. Tumor differentiation has been reported in the literature as a measure of the biological aggressiveness of a tumor and a predictor of long-term survival $[15,17,24,34]$. Therefore,

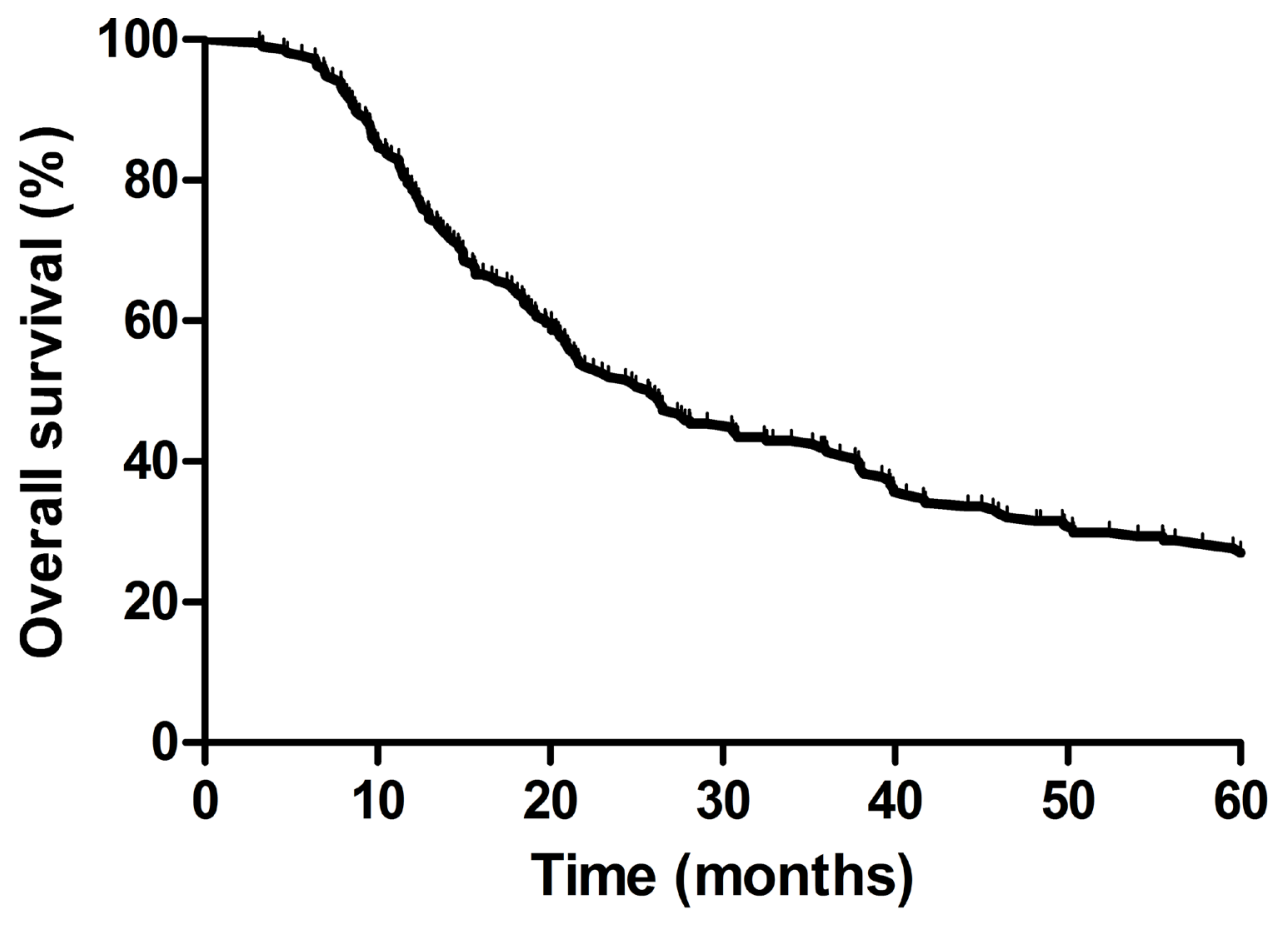

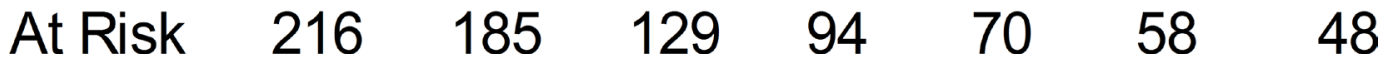

Figure 1: Overall survival of patients who underwent curative surgery for hilar cholangiocarcinoma. 
Table 3: Pathological and prognostic risk factors correlated with tumor size

\begin{tabular}{|c|c|c|c|c|c|}
\hline \multirow[b]{2}{*}{ Variable } & \multicolumn{5}{|c|}{ Tumor Size $(n=216)$} \\
\hline & $\leq 2 \mathrm{~cm}(n=88)$ & $2-3 \mathrm{~cm}(n=78)$ & $P^{*}$ & $>3 \mathrm{~cm}(n=50)$ & $P^{* k}$ \\
\hline \multicolumn{6}{|l|}{ Age } \\
\hline$\leq 60$ & $43(48.9)$ & $39(50.0)$ & NS & $26(52.0)$ & NS \\
\hline$>60$ & $45(51.1)$ & $39(50.0)$ & & $24(48.0)$ & \\
\hline \multicolumn{6}{|l|}{ Gender } \\
\hline male & $61(69.3)$ & $49(62.8)$ & NS & $30(60.0)$ & NS \\
\hline female & $27(30.7)$ & $29(37.2)$ & & $20(40.0)$ & \\
\hline \multicolumn{6}{|c|}{ Preoperative hospital stay } \\
\hline$\leq 8$ & $69(78.4)$ & $50(64.1)$ & 0.009 & $23(46.0)$ & 0.001 \\
\hline$>8$ & $19(21.6)$ & $28(35.9)$ & & $27(54.0)$ & \\
\hline \multicolumn{6}{|l|}{ Total hospital stay } \\
\hline$\leq 19$ & $59(67.0)$ & $41(52.6)$ & 0.002 & $16(32.0)$ & 0.003 \\
\hline$>19$ & $29(33.0)$ & $37(47.4)$ & & $34(68.0)$ & \\
\hline \multicolumn{6}{|l|}{ Surgical procedures } \\
\hline BDR & $20(22.7)$ & $10(12.8)$ & 0.046 & $6(12.0)$ & NS \\
\hline BDR+hepatectomy & $68(77.3)$ & $68(87.2)$ & & $44(88.0)$ & \\
\hline \multicolumn{6}{|l|}{ Caudate lobectomy } \\
\hline Yes & $72(81.8)$ & $70(89.7)$ & 0.047 & $45(90.0)$ & NS \\
\hline No & $16(18.2)$ & $8(10.3)$ & & $5(10.0)$ & \\
\hline \multicolumn{6}{|c|}{ Bismuth-Corlette classification } \\
\hline I and II & $51(58.0)$ & $31(39.7)$ & 0.04 & $25(50.0)$ & NS \\
\hline III and IV & $37(42.0)$ & $47(60.3)$ & & $25(50.0)$ & \\
\hline \multicolumn{6}{|l|}{ Gross feature } \\
\hline Infiltrating tumor & $58(65.9)$ & $57(73.1)$ & NS & $30(60.0)$ & 0.021 \\
\hline Nodular tumor & $20(22.7)$ & $13(16.7)$ & & $18(36.0)$ & \\
\hline Papillary tumor & $10(11.4)$ & $8(10.2)$ & & $2(14.0)$ & \\
\hline \multicolumn{6}{|l|}{ Differentiation } \\
\hline Poor & $13(14.8)$ & $19(24.4)$ & 0.008 & $24(48.0)$ & $<0.001$ \\
\hline Moderate & $47(53.4)$ & $37(47.4)$ & & $15(30.0)$ & \\
\hline Well & $28(31.8)$ & $22(28.2)$ & & $11(22.0)$ & \\
\hline \multicolumn{6}{|l|}{ Resection margin } \\
\hline Positive & $8(9.1)$ & $12(15.4)$ & 0.009 & $20(40.0)$ & 0.005 \\
\hline Negative & $80(90.9)$ & $66(84.6)$ & & $30(60.0)$ & \\
\hline \multicolumn{6}{|c|}{ lymph node metastasis } \\
\hline Yes & $27(30.7)$ & $33(42.3)$ & 0.001 & $35(70.0)$ & 0.002 \\
\hline No & $61(69.3)$ & $45(57.7)$ & & $15(30.0)$ & \\
\hline \multicolumn{6}{|l|}{ T stage (AJCC) } \\
\hline $\mathrm{T} 1 / \mathrm{T} 2$ & $55(62.5)$ & $34(43.6)$ & 0.005 & $21(42.0)$ & NS \\
\hline $\mathrm{T} 3 / \mathrm{T} 4$ & $33(37.5)$ & $44(56.4)$ & & $29(58.0)$ & \\
\hline \multicolumn{6}{|l|}{ Vascular invasion } \\
\hline Yes & $6(6.9)$ & $10(12.8)$ & 0.036 & $11(22.0)$ & 0.021 \\
\hline No & $82(93.1)$ & $68(87.2)$ & & $39(88.0)$ & \\
\hline
\end{tabular}

$\mathrm{P}^{*}$ : comparison between tumor size $\leq 2 \mathrm{~cm}$ versus tumor size $>2 \mathrm{~cm} ; \mathrm{P}^{* *}$ : comparison between tumor size $\leq 3 \mathrm{~cm}$ versus tumor size $>3 \mathrm{~cm}$; CA19-9: carbohydrate antigenic determinant 19-9; BDR: Bile ducts resection alone; AJCC: American Joint Committee on Cancer.

considering the finding that the $2-\mathrm{cm}$ and $3-\mathrm{cm}$ tumor size cutoffs were associated with tumor differentiation, it is unsurprising that they also predicted the overall survival. Thus, we consider that besides the current tumorsize cutoffs of 1 and $3 \mathrm{~cm}$, the 2-cm cutoff may also be included in the DeOliveira staging system. 
Table 4: Variables associated with tumor size in a multivariate logistic analysis

\begin{tabular}{|c|c|c|c|c|c|c|}
\hline \multirow{2}{*}{ Variables } & \multicolumn{3}{|c|}{$2 \mathrm{~cm}$ cut-off } & \multicolumn{3}{|c|}{$3 \mathrm{~cm}$ cut-off } \\
\hline & Odds ratio & $95 \% \mathrm{CI}$ & $P$ value & Odds ratio & $95 \% \mathrm{CI}$ & $P$ value \\
\hline Tumor resection margin & 2.465 & $1.024-5.937$ & 0.044 & 2.539 & $1.089-5.919$ & 0.031 \\
\hline Tumor differentiation & 1.649 & $1.065-2.555$ & 0.025 & 1.755 & $1.062-2.091$ & 0.028 \\
\hline Node status & 1.971 & $1.060-3.664$ & 0.032 & 2.166 & $1.054-4.452$ & 0.035 \\
\hline Total hospital stay & 2.428 & $1.327-4.441$ & 0.004 & 2.383 & $1.072-5.295$ & 0.033 \\
\hline Hepatectomy & 2.373 & $1.226-4.593$ & 0.010 & - & - & - \\
\hline
\end{tabular}

CI: confidence interval

A detailed analysis of the correlation between tumorsize cutoffs and lymph node metastasis highlighted the intimate relationship between tumor diameter and lymph node metastasis. Compared with 1-cm cutoff, the 2-cm and $3-\mathrm{cm}$ cutoffs were indeed associated with a higher proportion of lymph node metastasis. Node status has been proved to be an independent factor influencing the overall outcome in many recent research studies $[35,36]$. Thus, our results indicate that the $2-\mathrm{cm}$ and $3-\mathrm{cm}$ tumorsize cutoffs can indirectly affect the overall survival owing to their correlation with node status. We consider that the 2-cm cutoff may become a new potential tumor-size cutoff point in the DeOliveira staging system in future.

We further evaluated the relationship of different tumor-size cutoffs with resection margins. The $2-\mathrm{cm}$ and $3-\mathrm{cm}$ cutoffs were correlated with microscopically negative surgical margins. Specifically, the likelihood of achieving a microscopically negative margin decreased from $90.9 \%$ to $60 \%$ as the tumor size increased from $2 \mathrm{~cm}$ to $3 \mathrm{~cm}$ or larger. However, in the subgroups of patients with tumors measuring $\leq 2 \mathrm{~cm}$ and those measuring $>3$ $\mathrm{cm}$, we did not find any correlation between tumor size and resection margins. Thus, compared with 1-cm cutoff, the $2-\mathrm{cm}$ and $3-\mathrm{cm}$ cutoffs were strongly correlated with the resection margin. Furthermore, the importance of R0 resection margins in prolonging the overall survival rate has been frequently reported by many authors [27, 37, 38]. Our results showed that the $2-\mathrm{cm}$ and $3-\mathrm{cm}$ tumor-size cutoffs were strongly associated with resection margins and thus indirectly influenced postoperative survival outcomes to some extent. This finding further supports the addition of a 2-cm cutoff to the DeOliveira staging system.

Upon analyzing the relationship of different tumorsize cutoffs with surgical procedures, we found that the 2-cm cutoff was correlated with whether to carry out hepatectomy or not. Hepatectomy appears to have a positive effect on tumor-free margins and survival after the resection of Klatskin tumors [23, 39]. Thus, the 2-cm cutoff may be more important than the 3-cm cutoff because of its additional impact on the application of hepatectomy and indirect effect on survival outcomes. We therefore recommend that the $2-\mathrm{cm}$ cutoff be included in the DeOliveira staging system.
Consistent with the current DeOliveira staging system, our results indicated that the $3-\mathrm{cm}$ cutoff was a significant prognostic factor and that this cutoff point was reasonable for $\mathrm{HCCA}$, as tumors larger than $3 \mathrm{~cm}$ were more likely to be associated with a poor prognosis $[29,30]$. However, different from the existing DeOliveira staging system, our results showed that in addition to the $3-\mathrm{cm}$ tumor-size cutoff, the $2-\mathrm{cm}$ cutoff was also correlated with tumor differentiation, node status, and resection margins and indirectly affected long-term survival. Furthermore, it could affect the ability to carry out surgical procedures and further influence survival outcomes. In the current DeOliveira staging system, the $\mathrm{T}$ stage is classified according to tumor size into the TI $(<1 \mathrm{~cm})$, T2 $(1-3 \mathrm{~cm})$, and T3 $(>3 \mathrm{~cm})$ stages, which ignores the role of the $2-\mathrm{cm}$ tumor-size cutoff. Thus, our findings might complement the current DeOliveira staging system, and the 2-cm cutoff may become another potential tumor-size cutoff in the new DeOliveira staging system.

Also, different from the existing staging system, our study did not find an association of the 1-cm cutoff with prognostic factors and survival. In their research, DeOliveira et al. only interpreted the reason for selecting the 3-cm cutoff for defining T3 tumors; they did not explain why the 1-cm cutoff was selected as the first cutoff point [31]. Because of the late presentation of symptoms in HCCA, these tumors are usually diagnosed in the later stages when the disease is locally advanced. Thus, most patients have tumors measuring $>1 \mathrm{~cm}$, which is supported by our current findings. So this classification needs to be further evaluated in a large case series or multi-center clinical research study.

In conclusion, our data confirm the notion that compared with the $1-\mathrm{cm}$ tumor-size cutoff, the $2-\mathrm{cm}$ and $3-\mathrm{cm}$ cutoffs were more important in terms of their association with survival and other prognostic factors. Compared with patients with tumors measuring $\leq 2 \mathrm{~cm}$, those with tumors measuring $>3 \mathrm{~cm}$ were more likely to have poorly differentiated tumors, $\mathrm{R} 1$ or $\mathrm{R} 2$ resection margins, and lymph node metastasis. The $2-\mathrm{cm}$ and $3-\mathrm{cm}$ tumor-size cutoffs could also affect the overall survival outcome by indirectly influencing tumor differentiation, tumor resection margins, and node status. The $2-\mathrm{cm}$ and 
3-cm tumor-size cutoffs maybe more reasonable than the current $1-\mathrm{cm}$ and $3-\mathrm{cm}$ cutoffs. At the very least, the $2-\mathrm{cm}$ cutoff should be considered as another potential tumor-size cutoff point in the current DeOliveira staging system; however, further research is urgently warranted to clinically test the rationality of the present results.

\section{MATERIALS AND METHODS}

\section{Study population and data collection}

Patients with pathologically verified HCCA from January 2000 to January 2013 were retrospectively involved after curative resection and clinical, radiologic, pathologic, intraoperative and survival data were systematically analyzed. Periampullary carcinomas, gallbladder cancers, or intrahepatic cholangiocarcinomas and those who underwent palliative surgery were excluded from this study. Total of 216 patients were divided into three groups based on tumor size: A: $\leq 2 \mathrm{~cm}(n=88)$, B: $2-3 \mathrm{~cm}(n=78), \mathrm{C}:>3 \mathrm{~cm}(n=50)$. Tumor size $\leq 2 \mathrm{~cm}$ was further divided into two subgroups: tumor size $\leq 1 \mathrm{~cm}$ $(n=21)$ and tumor size $1-2 \mathrm{~cm}(n=67)$. Similarly, tumor size $>3 \mathrm{~cm}$ was also divided into two subgroups: tumor size 3-4 $\mathrm{cm}(n=39)$ and tumor size $>4 \mathrm{~cm}(n=11)$.

\section{Preoperative evaluation}

Patients were evaluated with a baseline of medical history, detailed physical examination, full blood count, liver function tests, serum carcinoembryonic antigen (CEA) and cancer antigen 19-9 (CA19-9) assays.
Abdominal ultrasonography and abdominothoracic computed tomography were systematically performed to evaluate local and distant tumor involvement. Magnetic Resonance Cholangiopancreatography was used in patients who were considered to have potentially resectable tumors. Preoperative biliary decompression was performed in patients with cholangitis or obstructive jaundice $(>5 \mathrm{mg} / \mathrm{dL})$ through percutaneous transhepatic biliary drainage or endoscopic biliary drainage. Portal vein embolization was mainly carried out on patients with compromised liver function when the anticipated future remnant volume was less than $25 \%$ of the total liver volume, in order to minimize postoperative hepatic failure risk. Resection procedures were selected according to preoperative imaging and intraoperative evaluation by experienced operating surgeons.

\section{Surgical procedures and tumor classification}

The standard treatment as per our hospital guideline was biliary confluence resection combined with major hepatectomy and lymphadenectomy. The results of surgical procedures of patients with hilar cholangiocarcinoma are presented in Figure 2, of which portal vein resection and reconstruction was performed in $26(12.0 \%)$ patients, en bloc caudate was routinely removed in $187(86.6 \%)$ of these patients and patients that did not involve caudate lobe resection were early cases of type I papillary carcinoma. Intra-operative frozen section of resected bile ducts and liver parenchyma margin were routinely examined to guide resection. Biliary continuity was restored by Roux-en-Y choledocho-jejunostomy.

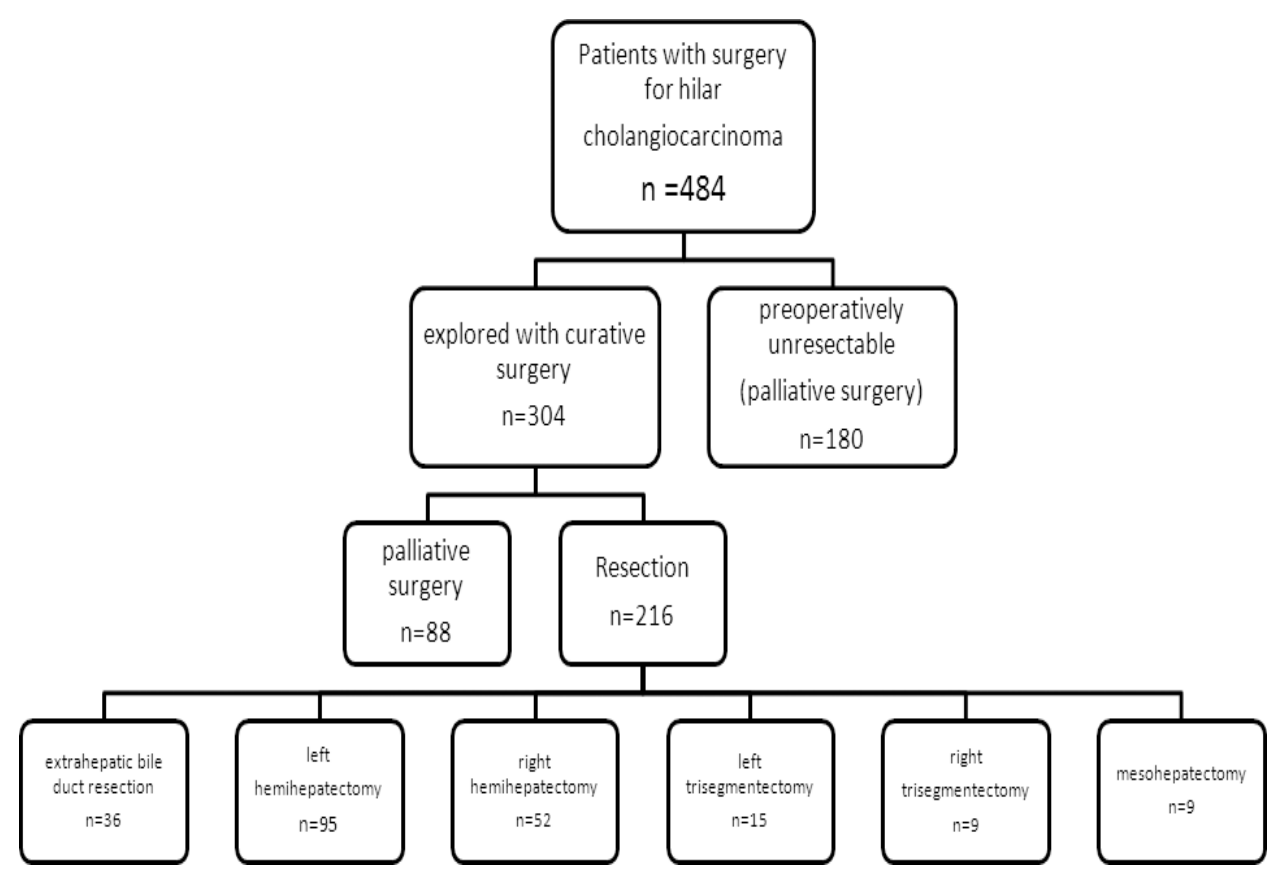

Figure 2: Flow diagram showing the results of surgical procedures of all patients with hilar cholangiocarcinoma in our series. 


\section{Statistical analysis}

Frequency and descriptive analysis were applied to describe patient characteristics. Univariate and bivariate analysis was used to discuss the association of several variables, including gender, age, CA199 level, preoperative biliary drainage, vascular invasion, surgical procedures, gross feature, Bismuth-Corlette classification, tumor staging (AJCC), tumor resection margin, tumor differentiation, node status and postoperative complications et al. with different cut-offs of tumor size. The significant factors $(P<0.10)$ identified by univariate analysis were included in a multivariate logistic regression to investigate the influence of these covariates on tumor size. The two-sided $P$ values of $<0.05$ were considered significant. Statistical analysis was performed using SPSS version16.0 (SPSS Inc, Chicago IL).

\section{Abbreviations}

HCCA: Hilar cholangiocarcinoma; OR: odds ratio; CI: confidence interval; CA19-9: cancer antigen 19-9.

\section{Author contributions}

Hai-Jie Hu and Rong-Xing Zhou contributed equally to this paper. Hai-Jie Hu and Rong-Xing Zhou contributed to the analysis and drafted the manuscript. Wen-Jie Ma, Qin Yang and Jun-Ke Wang contributed to data acquisition and analyzed the manuscript. Anuj Shrestha, Yong-Qiong Tan and Jiong $\mathrm{Lu}$ were involved in the revision of the manuscript. Fu-Yu Li and Yong Zhou contributed to the study design and revision of the manuscript. All authors read and approved the final manuscript.

\section{ACKNOWLEDGMENTS AND FUNDING}

The authors acknowledge the financial support from National Nature Science of China (30801111, 30972923) and Science \& Technology Support Project of Sichuan Province (2014SZ0002-10, 2014FZ0049, 2015FZ0076).

\section{CONFLICTS OF INTEREST}

We declare that we have no competing interests.

\section{REFERENCES}

1. Li H, Qin Y, Cui Y, Chen H, Hao X, Li Q. Analysis of the surgical outcome and prognostic factors for hilar cholangiocarcinoma: a Chinese experience. Dig Surg. 2011; 28:226-31.

2. Gazzaniga GM, Filauro M, Bagarolo C, Mori L. Surgery for hilar cholangiocarcinoma: an Italian experience. J Hepatobiliary Pancreat Surg. 2000; 7:122-7.
3. Launois B, Reding R, Lebeau G, Buard JL. Surgery for hilar cholangiocarcinoma: French experience in a collective survey of 552 extrahepatic bile duct cancers. J Hepatobiliary Pancreat Surg. 2000; 7:128-34.

4. Jarnagin WR, Bowne W, Klimstra DS, Ben-Porat L, Roggin K, Cymes K, Fong Y, DeMatteo RP, D'Angelica M, Koea J, Blumgart LH. Papillary Phenotype Confers Improved Survival After Resection of Hilar Cholangiocarcinoma. Ann Surg. 2005; 241:703-14.

5. Baton O, Azoulay D, Adam DV, Castaing D. Major hepatectomy for hilar cholangiocarcinoma type 3 and 4 : prognostic factors and longterm outcomes. J Am Coll Surg. 2007; 204:250-60.

6. Klempnauer J, Ridder GJ, Werner M, Weimann A, Pichlmayr $\mathrm{R}$. What constitutes long term survival after surgery for hilar cholangiocarcinoma? Cancer. 1997; 79:26-34.

7. Hidalgo E, Asthana S, Nishio H, Wyatt J, Toogood GJ, Prasad KR, Lodge JP. Surgery for hilar cholangiocarcinoma: the Leeds experience. Eur J Surg Oncol. 2008; 34:787-94.

8. Ercolani G, Zanello M, Grazi GL, Cescon M, Ravaioli M, Del Gaudio M, Vetrone G, Cucchetti A, Brandi G, Ramacciato G, Pinna AD. Changes in the surgical approach to hilar cholangiocarcinoma during an 18-year period in a Western single center. J Hepatobiliary Pancreat Sci. 2010; 17:329-37.

9. Hemming AW, Reed AI, Fujita S, Foley DP, Howard RJ. Surgical Management of Hilar Cholangiocarcinoma. Ann Surg. 2005; 241:693-702.

10. Otto G. Diagnostic and surgical approaches in hilar cholangiocarcinoma. Int J Colorectal Dis. 2007; 22:101-8.

11. Jarnagin WR, Fong Y, DeMatteo RP, Gonen M, Burke EC, Bodniewicz BJ, Youssef BM, Klimstra D, Blumgart LH. Staging, resectability, and outcome in 225 patients with hilar cholangiocarcinoma. Ann Surg. 2001; 234:507-17; discussion 17-9.

12. Ruys AT, van Haelst S, Busch OR, Rauws EA, Gouma DJ, van Gulik TM. Long-term Survival in Hilar Cholangiocarcinoma also Possible in Unresectable Patients. World J Surg. 2012; 36:2179-86.

13. Dumitrascu T, Chirita D, Ionescu M, Popescu I. Resection for hilar cholangiocarcinoma: analysis of prognostic factors and the impact of systemic inflammation on long-term outcome. J Gastrointest Surg. 2013; 17:913-24.

14. Weber SM, DeMatteo RP, Fong Y, Blumgart LH, Jarnagin WR. Staging laparoscopy in patients with extrahepatic biliary carcinoma. Analysis of 100 patients. Ann Surg. 2002; 235:392-9.

15. Saxena A, Chua TC, Chu FC, Morris DL. Improved outcomes after aggressive surgical resection of hilar cholangiocarcinoma: a critical analysis of recurrence and survival. Am J Surg. 2011; 202:310-20.

16. Chen XP, Lau WY, Huang ZY, Zhang ZW, Chen YF, Zhang WG, Qiu FZ. Extent of liver resection for hilar cholangiocarcinoma. Br J Surg. 2009; 96:1167-75. 
17. Jang JY, Kim SW, Park DJ, Ahn YJ, Yoon YS, Choi MG, Suh KS, Lee KU, Park YH. Actual long-term outcome of extrahepatic bile duct cancer after surgical resection. Ann Surg. 2005; 241:77-84.

18. Hemming AW, Reed AI, Langham MR, Fujita S, Howard RJ. Combined Resection of the Liver and Inferior Vena Cava for Hepatic Malignancy. Ann Surg 2004; 239:712-21.

19. Croome KP, Rosen CB, Heimbach JK, Nagorney DM. Is Liver Transplantation Appropriate for Patients with Potentially Resectable De Novo Hilar Cholangiocarcinoma? J Am Coll Surg. 2015; 221:130-9.

20. Wang Y, Yang H, Shen C, Luo J. Surgical procedure and long-term survival of hilar cholangiocarcinoma. Int J Clin Exp Med. 2015; 8:1122-8.

21. Klempnauer J, Ridder GJ, von Wasielewski R, Werner M, Weimann A, Pichlmayr R. Resectional surgery of hilar cholangiocarcinoma: a multivariate analysis of prognostic factors. J Clin Oncol. 1997; 15:947-54.

22. DeOliveira ML, Cunningham SC, Cameron JL, Kamangar F, Winter JM, Lillemoe KD, Choti MA, Yeo CJ, Schulick RD. Cholangiocarcinoma: thirty-one-year experience with 564 patients at a single institution. Ann Surg. 2007; 245:755-62.

23. Kow AW, Wook CD, Song SC, Kim WS, Kim MJ, Park HJ, Heo JS, Choi SH. Role of caudate lobectomy in type III A and III B hilar cholangiocarcinoma: a 15-year experience in a tertiary institution. World J Surg. 2012; 36:1112-21.

24. Ito F, Agni R, Rettammel RJ, Been MJ, Cho CS, Mahvi DM, Rikkers LF, Weber SM. Resection of hilar cholangiocarcinoma: concomitant liver resection decreases hepatic recurrence. Ann Surg. 2008; 248:273-9.

25. Hemming AW, Mekeel K, Khanna A, Baquerizo A, Kim RD. Portal vein resection in management of hilar cholangiocarcinoma. J Am Coll Surg. 2011; 212:604-13; discussion 13-6.

26. Ramacciato G, Nigri G, Bellagamba R, Petrucciani N, Ravaioli M, Cescon M, Del Gaudio M, Ercolani G, Di Benedetto F, Cautero N, Quintini C, Cucchetti A, Lauro A, et al. Univariate and multivariate analysis of prognostic factors in the surgical treatment of hilar cholangiocarcinoma. Am Surg. 2010; 76:1260-8.

27. Cheng QB, Yi B, Wang JH, Jiang XQ, Luo XJ, Liu C, Ran RZ, Yan PN, Zhang BH. Resection with total caudate lobectomy confers survival benefit in hilar cholangiocarcinoma of Bismuth type III and IV. Eur J Surg Oncol. 2012; 38:1197-203.

28. Hakeem AR, Marangoni G, Chapman SJ, Young RS, Nair A, Hidalgo EL, Toogood GJ, Wyatt JI, Lodge PA, Prasad KR. Does the extent of lymphadenectomy, number of lymph nodes, positive lymph node ratio and neutrophillymphocyte ratio impact surgical outcome of perihilar cholangiocarcinoma? Eur J Gastroenterol Hepatol. 2014; 26:1047-54.
29. Regimbeau JM, Fuks D, Pessaux P, Bachellier P, Chatelain D, Diouf M, Raventos A, Mantion G, Gigot JF, Chiche L, Pascal G, Azoulay D, Laurent A, et al. Tumour size over $3 \mathrm{~cm}$ predicts poor short-term outcomes after major liver resection for hilar cholangiocarcinoma. By the HCAFC-2009 group. HPB (Oxford). 2015; 17:79-86.

30. Chaiteerakij R, Harmsen WS, Marrero CR, Aboelsoud MM, Ndzengue A, Kaiya J, Therneau TM, Sanchez W, Gores GJ, Roberts LR. A new clinically based staging system for perihilar cholangiocarcinoma. Am J Gastroenterol. 2014; 109:1881-90.

31. Deoliveira ML, Schulick RD, Nimura Y, Rosen C, Gores G, Neuhaus P, Clavien PA. New staging system and a registry for perihilar cholangiocarcinoma. Hepatology. 2011; 53:1363-71.

32. Popescu I, Dumitrascu T. Curative-intent surgery for hilar cholangiocarcinoma: prognostic factors for clinical decision making. Langenbecks Arch Surg. 2014; 399:693-705.

33. Kim K, Chie EK, Jang JY, Kim SW, Han SW, Oh DY, Im SA, Kim TY, Bang YJ, Ha SW. Distant metastasis risk stratification for patients undergoing curative resection followed by adjuvant chemoradiation for extrahepatic bile duct cancer. Int J Radiat Oncol Biol Phys. 2012; 84:81-7.

34. Su CH, Tsay SH, Wu CC, Shyr YM, King KL, Lee CH, Lui WY, Liu TJ, P'eng FK. Factors influencing postoperative morbidity, mortality, and survival after resection for hilar cholangiocarcinoma. Ann Surg. 1996; 223:384-94.

35. Lee SG, Song GW, Hwang S, Ha TY, Moon DB, Jung DH, Kim KH, Ahn CS, Kim MH, Lee SK, Sung KB, Ko GY. Surgical treatment of hilar cholangiocarcinoma in the new era: the Asan experience. J Hepatobiliary Pancreat Sci. 2010; 17:476-89.

36. Ebata T, Nagino M, Kamiya J, Uesaka K, Nagasaka T, Nimura Y. Hepatectomy with portal vein resection for hilar cholangiocarcinoma: audit of 52 consecutive cases. Ann Surg. 2003; 238:720-7.

37. Ito $\mathrm{F}$, Cho CS, Rikkers LF, Weber SM. Hilar cholangiocarcinoma: current management. Ann Surg. 2009; 250:210-8.

38. Nuzzo G, Giuliante F, Ardito F, Giovannini I, Aldrighetti L, Belli G, Bresadola F, Calise F, Dalla Valle R, D'Amico DF, Gennari L, Giulini SM, Guglielmi A, et al. Improvement in perioperative and long-term outcome after surgical treatment of hilar cholangiocarcinoma: results of an Italian multicenter analysis of 440 patients. Arch Surg. 2012; 147:26-34.

39. Dinant S, Gerhards MF, Rauws EA, Busch OR, Gouma DJ, van Gulik TM. Improved outcome of resection of hilar cholangiocarcinoma (Klatskin tumor). Ann Surg Oncol. 2006; 13:872-80. 